Universidad de Lima

Facultad de Derecho

Carrera de Derecho

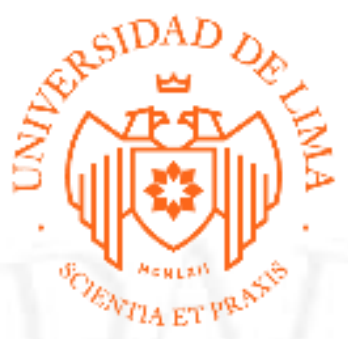

\title{
CIVIL: "OBLIGACIÓN DE DAR SUMA DE DINERO" Y REGISTRAL: "INSCRIPCIÓN DEL TÍTULO"
}

Trabajo de suficiencia profesional para optar el Título Profesional de Abogado

\author{
José Carlos Pérez Rivera
}

Código 20120999

$$
\text { Lima - Perú }
$$

Octubre de 2019 


\title{
CIVIL: “OBLIGACIÓN DE DAR SUMA DE DINERO"
}

Materia: Obligación de dar suma de dinero

$\mathrm{N}^{\mathrm{o}}$ de Expediente: 1852-2002

\begin{abstract}
RESUMEN
Se trata de un expediente en el que, con fecha 30 de enero de 2007, las demandantes interponen una demanda de obligación de dar suma de dinero contra una Municipalidad con la finalidad que la segunda cumplan con pagar a las primeras la suma de 24,707.08(veinticuatro mil setecientos siete con 08/100)por concepto de intereses legales correspondientes a un proceso seguido ante el Primer Juzgado Civil del Callao sobre Acción de cumplimiento
\end{abstract}

\section{REGISTRAL: "INSCRIPCIÓN DEL TÍTULO"}

Materia: Registral

No de Título de solicitud de inscripción: 2014-932375

\section{RESUMEN}

Se trata de un caso en el que la cuestión en controversia es determinar si para la inscripción de la renuncia de un apoderado de una sociedad es requisito que la carta de renuncia con constancia notarial se dirija al domicilio que la sociedad declaró y fijó ante SUNAT. 